\title{
Usefulness of the "newly designed" short-type single-balloon enteroscope for ERCP in patients with Roux-en-Y gastrectomy: a pilot study
}

\section{๑(®९)}

\author{
Authors \\ Yuki Tanisaka', Shomei Ryozawa', Masafumi Mizuide ${ }^{1}$, Masanori Kobayashi ${ }^{1}$, Akashi Fujita ${ }^{1}$, Kazuhiro Minami ${ }^{1}$, \\ Tsutomu Kobatake ${ }^{1}$, Kumiko Omiya ${ }^{1}$, Hirotoshi Iwano ${ }^{1}$, Ryuichiro Araki ${ }^{2}$
}

Institutions

1 Department of Gastroenterology, Saitama Medical University International Medical Center, Saitama, Japan

2 Community Health Science Center, Saitama Medical University, Saitama, Japan

submitted 7.5.2018

accepted after revision 22.8 .2018

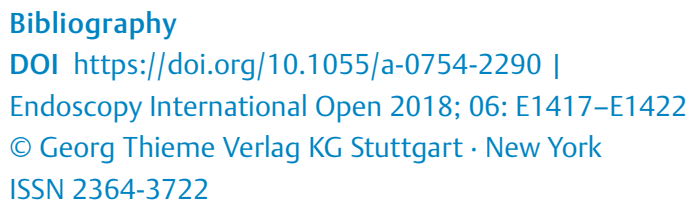

\section{ABSTRACT}

Background and aims In recent years, the short singleballoon enteroscope (SBE) has been used during endoscopic retrograde cholangiopancreatography (ERCP) for patients with surgically altered anatomy and has been reported to be useful. However, difficulties remain, and the procedures and devices need improvements. We assessed the usefulness and superiority of a new short SBE equipped with passive bending and high-force transmission by comparisons with outcomes using the conventional short SBE. Methods This study evaluated short SBE-assisted ERCPrelated procedures for Roux-en-Y gastrectomy between September 2011 and October 2017. Outcomes including the procedural success rate, which was the primary outcome, were assessed to compare the conventional short SBE (SIF-Y0004 [prototype]) and the new short SBE (SIFH290S).

Results Of 74 procedures performed in 61 patients, 51 procedures in 39 patients involved the SIF-Y0004, and 23 procedures in 22 patients involved the SIF-H290S. The procedural success rates were $70.6 \%$ for SIF-Y0004, and $95.7 \%$ for SIF-H290S, representing better results for the new short SBE $(P=0.02)$. The new short SBE also had a superior diagnostic success rate $(P=0.047)$ and median time to reach the blind end $(P<0.001)$.

Conclusions Roux-en-Y gastrectomy patients treated with the new short SBE had better outcomes than those treated with conventional short SBE. More cases need to be studied; however, the new short SBE has the potential to improve ERCP outcomes in patients with surgically altered anatomy.

\section{Background}

Endoscopic retrograde cholangiopancreatography (ERCP) in patients with surgically altered anatomy is thought to be difficult, because postoperative adhesions and certain anatomical characteristics such as long distance from the anastomosis or flexion make it difficult to insert an endoscope to reach the papilla or choledochojejunoanstomosis. Furthermore, bile duct cannulation and subsequent treatments are also more difficult than treatments using a duodenoscope with normal anatomy, and outcomes have not been satisfactory [1,2]. Therefore, per- cutaneous or surgical therapy is often selected instead of endoscopic therapy.

The double-balloon enteroscope (DBE), developed to diagnose and treat small-bowel disease, was introduced in 2001 [3], and DBE-assisted ERCP has been described as useful [4 - 7]. Furthermore, single-balloon enteroscope (SBE)-assisted ERCP has also been reported to be effective [8-10]. A short SBE, with a working length of $152 \mathrm{~cm}$ and a $3.2-\mathrm{mm}$ working channel, has also been developed, thus adding to the number of useful devices that can be used for ERCP treatment [11 - 15]. However, 
it is not uncommon for problems to arise because the scope cannot move forward when passing through sharp-angled parts of the intestinal tract during scope insertion. A newly designed short SBE equipped with passive bending and high-force transmission has been developed in recent years to solve this problem. This device has the potential to improve the success rates of scope insertion to the target site and subsequent ERCP-related procedures and to shorten treatment times. Roux-en-Y gastrectomy represents a particularly challenging form of reconstruction because of the difficulty of scope insertion due to the long distance to the target site, the involvement of intestinal adhesions, and the difficulty with cannulation of the papilla and subsequent treatment procedures. Outcomes using the new short SBE for Roux-en-Y gastrectomy patients were assessed by comparisons with outcomes using the conventional short SBE to determine whether the newly designed short SBE contributes to improved outcomes.

\section{Methods}

\section{Patients}

The subjects of this study were patients who underwent ERCPrelated procedures for Roux-en-Y gastrectomy between September 2011 and October 2017. The outcomes of bile ductrelated procedures were assessed. Those patients who underwent pancreatic duct treatments were excluded because at the moment, we have experienced few cases of these procedures using the new short SBE.

\section{Procedure using short SBE}

All treatments performed during this study involved a short SBE. Two types of scope were used: SIF-Y0004 (prototype) and SIF-H290S (new model; Olympus Medical Systems, Tokyo, Japan), which have a working length of $152 \mathrm{~cm}$ and a $3.2-\mathrm{mm}$ working channel. Table 1 shows the specifications of the endoscopes, including the SIF-Q260 (Olympus Medical Systems), which is the conventional SBE. Our facility has used the SIF-H290S since March 2016 ( $\bullet$ Fig. 1).

The new short SBE has two features: passive bending and high-force transmission. There is a passive bending section behind the scope curvature ( $\triangleright$ Fig. 2 ). If the scope is at the intestinal tract wall when passing through a sharp flexure, then the passive bending section allows the scope to smoothly bend along the bend of the wall, making it possible to move forward. High-force transmission capabilities make it possible to perform torque operations efficiently and to provide finer scope control. Therefore, it is also useful for bile duct cannulation and subsequent treatment procedures ( $\triangleright$ Fig. 2 ).

All ERCP treatments were performed using $\mathrm{CO}_{2}$ insufflation, and we used a distal attachment cap (D-201-10704; Olympus Medical Systems) in all cases. The patient was generally in the prone position; when insertion was difficult, the position was changed or abdominal compression was used.
Table 1 Specifications of single-balloon enteroscopes.

\begin{tabular}{|l|l|l|l|}
\hline & SIF-H290S & SIF-Y0004 & SIF-Q260 \\
\hline Field of view & $140^{\circ}$ & $120^{\circ}$ & $140^{\circ}$ \\
\hline Outer diameter, mm & 9.2 & 9.2 & 9.2 \\
\hline $\begin{array}{l}\text { Working channel } \\
\text { diameter, mm }\end{array}$ & 3.2 & 3.2 & 2.8 \\
\hline \begin{tabular}{l} 
Working length, mm \\
\hline Total length, mm
\end{tabular} & 1520 & 1520 & 2000 \\
\hline $\begin{array}{l}\text { Passive bending and } \\
\text { high force transmission }\end{array}$ & Yes & 1840 & 2345 \\
\hline
\end{tabular}

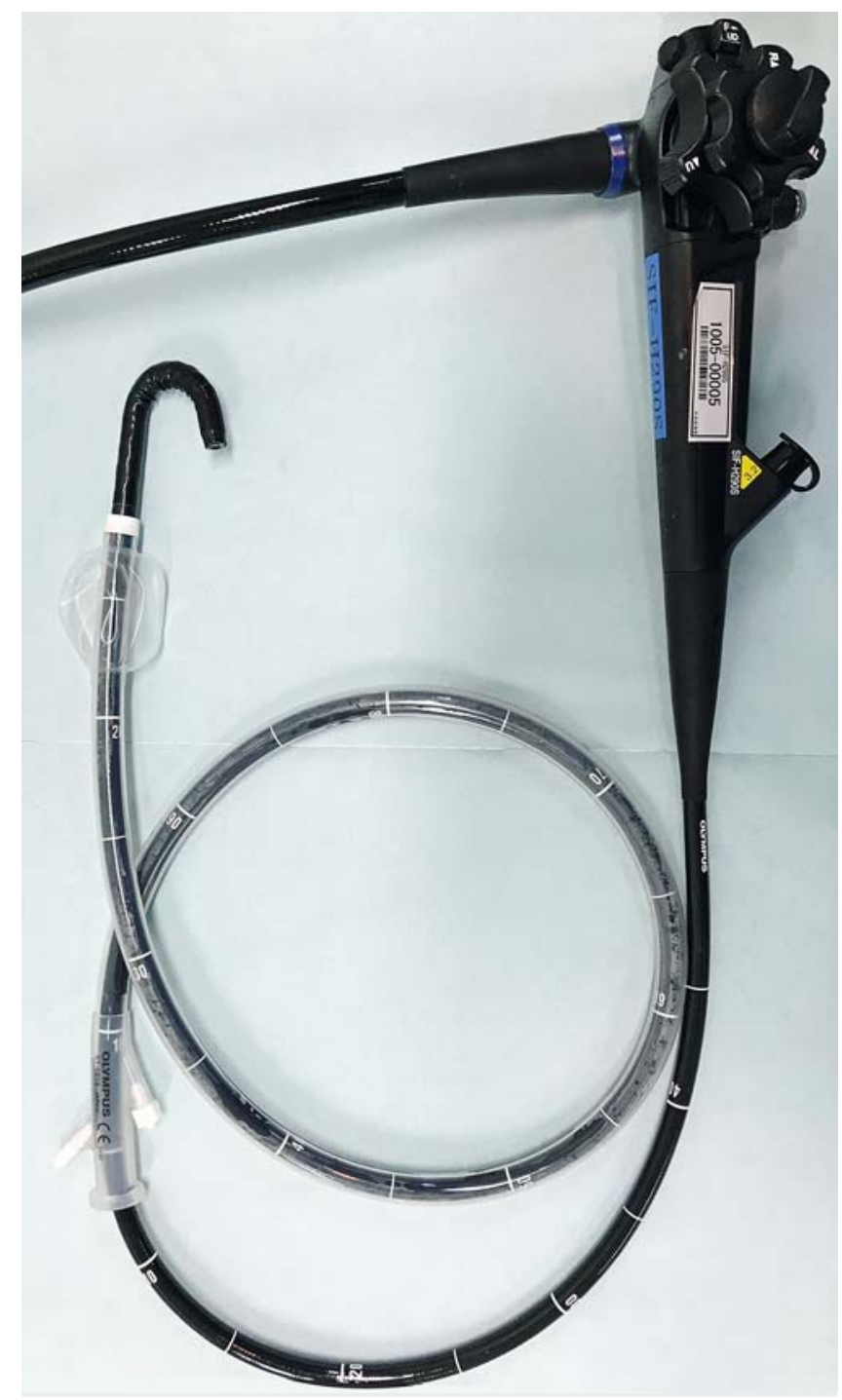

- Fig. 1 Newly designed short-type single-balloon endoscope (short SBE) (SIF-H290S) with a sliding tube. 


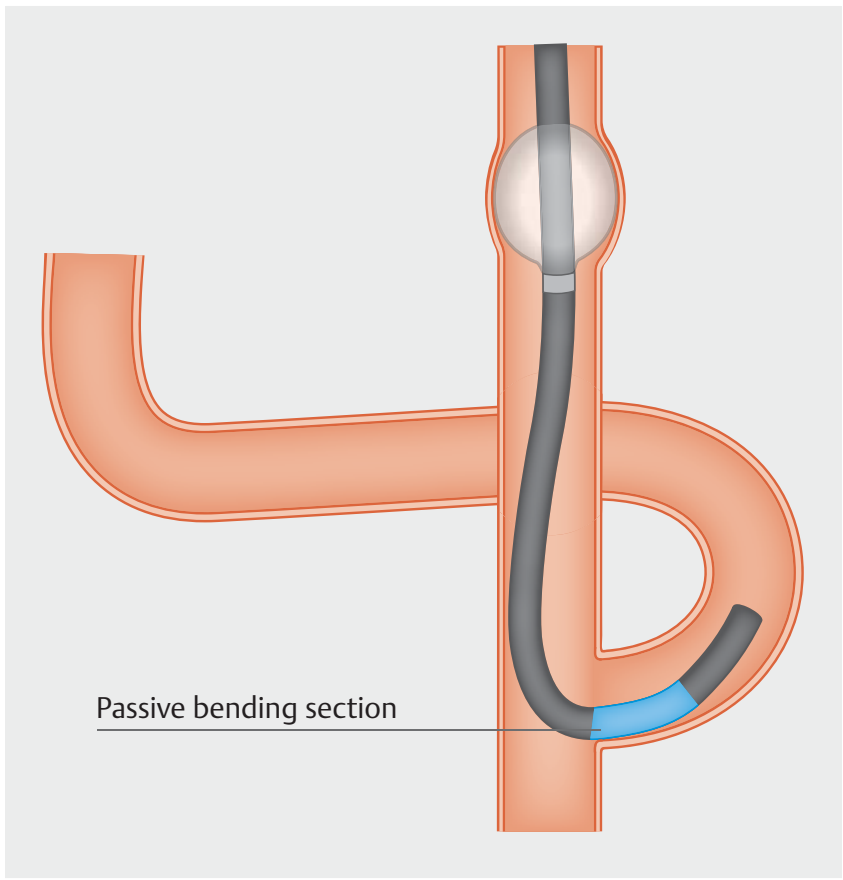

Fig. 2 Passive bending section of new short-type SBE. The passive bending section allows the scope to smoothly bend along the bend of the wall, making it possible to move forward.

\section{Definitions and outcome measurements}

This was a retrospective, single-center study that was approved by the Institutional Review Board at Saitama Medical University International Medical Center (17-052). Subjects were divided into one group who underwent ERCP-related procedures using the conventional short SBE (SIF-Y0004) and one group who underwent procedures using the new short SBE (SIF-H290S). The SIF-Y0004 was used in all cases before March 2016, and the SIF-H290S was used in all cases from March 2016 onwards. The primary outcome was the procedural success rate, which was assessed to compare outcomes between the two groups. The procedural success rate was the rate of successful completion from scope insertion to the intended treatment (e.g., stone extraction, stent placement, etc.). Other end points studied were the enteroscopy success rate, diagnostic success rate, median time to reach the blind end, median ERCP procedure time, and adverse events. The enteroscopy success rate was the rate of arrival at the papilla after scope insertion. Diagnostic success rate was the rate of successful bile duct cannulation and cholangiography when the papilla was successfully reached. ERCP procedure time was defined from starting bile duct cannulation to removal of the SBE. Adverse events were assessed in accordance with the American Society for Gastrointestinal Endoscopy severity grading system [16].

The study involved four endoscopists, and each endoscopist had performed at least 500 ERCP procedures with normal anatomy. In individual cases, the same endoscopist performed all procedures from scope insertion to treatment. Endoscopists who used the new short SBE had fewer experiences of SBE-assisted ERCP before this study, and the endoscopists who performed
Table 2 Number of patients and experience of the four endoscopists.

\begin{tabular}{|l|r|r|r|r|}
\hline & \multicolumn{3}{|c|}{ Endoscopist } \\
\hline & A & B & C & D \\
\hline $\begin{array}{l}\text { Experience with SBE-assisted ERCP } \\
\text { before this study, n }\end{array}$ & 65 & 26 & 3 & 0 \\
\hline $\begin{array}{l}\text { Number of cases in this study } \\
\text { - SIF-Y0004, n }\end{array}$ & 14 & 23 & 10 & 2 \\
\hline - SIF-H290S, n & 0 & 2 & 5 & 16 \\
\hline
\end{tabular}

the procedures using the conventional short SBE performed $9 \%$ of the cases using the new short SBE ( $\triangleright$ Table 2). All patients provided informed consent before undergoing treatment.

\section{Statistical analysis}

Two-group comparisons of age, time to reach the blind end, $\mathrm{BMI}$, and ERCP procedure time were conducted using the Mann-Whitney test. The reconstruction method, sex differences, other abdominal surgeries, reasons for ERCP, condition of the papilla, enteroscopy success rate, diagnostic success rate, procedural success rate, and adverse events were analyzed using Fisher's exact probability test. SAS JMP version 12.2.0 and SAS version 9.1.3 SP4 (SAS Institute Inc., Cary, North Carolina, United States) were used for statistical analyses; $P<0.05$ indicated statistical significance.

\section{Results}

\section{Patients}

During the study period, we performed 74 procedures in 61 Roux-en-Y gastrectomy patients. The SIF-Y0004 was used for 51 procedures in 39 patients while the SIF-H290S was used for 23 procedures in 22 patients. The two groups did not differ in the proportion of native papillae, BMI, other abdominal surgeries, or total versus partial gastrectomy ( $\bullet$ Table 3 ).

\section{Endoscopic procedure}

The procedural success rate, which was the primary outcome, was $78.4 \%$ overall ( $95 \%$ confidence interval [CI], $67.8-86.2 \%$ ). It was $70.6 \%(95 \% \mathrm{Cl}, 57.0-81.3 \%)$ for the SIF-Y0004 group and $95.7 \%(95 \% \mathrm{Cl}, 79.0-99.8 \%)$ for the SIF-H290S group, representing significantly better outcomes for the new short SBE group $(P=0.02)(\triangleright$ Table 4$)$. The enteroscopy success rate was $90.2 \%(95 \% \mathrm{Cl}, 79.0-95.7 \%)$ for the SIF-Y0004 group and $95.7 \%(95 \% \mathrm{Cl}, 79.0-99.8 \%)$ for SIF-H290S group and there was no statistically significant difference between the two groups $(P=0.66)$. Using the SIF-H290S, the target site could not be reached in one case because of strong adhesion in the intestinal tract. Diagnostic success rate was $82.6 \%(95 \% \mathrm{Cl}$, $69.3-90.9 \%)$ when using the SIF-Y0004, and $100 \%(95 \% \mathrm{Cl}$, $85.1-100 \%$ ) when using the SIF-H290S, thus indicating significantly better outcomes for the new short SBE group $(P=0.047)$.

Median time to reach the blind end was 29.5 minutes (interquartile range [IQR], 14.5-41.8) for the SIF-Y0004 group and 
- Table 3 Patient characteristics.

\begin{tabular}{|c|c|c|c|c|}
\hline & SIF-Y0004 & SIF-H290S & $P$ value & Total \\
\hline Number of patients & 39 & 22 & & 61 \\
\hline Age, median (IQR), years & $71(66.0-76.0)$ & $72.5(62.3-78.8)$ & 0.88 & $71(64.5-76.5)$ \\
\hline \multicolumn{5}{|l|}{ Sex } \\
\hline - Male, n (\%) & $27(69.2)$ & $19(86.4)$ & 0.22 & $46(75.4)$ \\
\hline - Female, n (\%) & $12(30.8)$ & $3(13.6)$ & & $15(24.6)$ \\
\hline \multicolumn{5}{|l|}{ Reconstruction method } \\
\hline - Roux-en-Y total gastrectomy, n (\%) & $23(59.0)$ & $17(77.3)$ & 0.17 & $40(65.6)$ \\
\hline - Roux-en-Y partial gastrectomy, n (\%) & $16(41.0)$ & $5(22.7)$ & & $21(34.4)$ \\
\hline BMI, median (IQR), kg/m² & $20.03(16.73-21.92)$ & $19.13(18.57-20.93)$ & 0.89 & $19.44(17.81-21.83)$ \\
\hline Other abdominal surgeries, $\mathrm{n}(\%)$ & $15(38.5)$ & $6(27.3)$ & 0.42 & $21(34.4)$ \\
\hline \multicolumn{5}{|l|}{ Reasons for ERCP } \\
\hline - Bile duct stone, n (\%) & $25(64.1)$ & $16(72.7)$ & 0.58 & $41(67.2)$ \\
\hline - Malignant stricture of bile duct, n (\%) & $14(35.9)$ & $6(27.3)$ & & $20(32.8)$ \\
\hline \multicolumn{5}{|l|}{ Papillae } \\
\hline - Native papillae, n (\%) & $38(97.4)$ & $20(90.9)$ & 0.29 & $58(95.1)$ \\
\hline - Post-procedure papillae, n (\%) & $1(2.6)$ & $2(9.1)$ & & $3(4.9)$ \\
\hline
\end{tabular}

- Table 4 Summary of procedure results ( $\mathrm{n}=74$ procedures).

\begin{tabular}{|l|l|l|l|l|}
\hline & SIF-Y0004 & SIF-H290S & P value & Total \\
\hline Number of procedures & 51 & 23 & 74 \\
\hline Enteroscopy success rate, \% (n) & $90.2(46 / 51)$ & $95.7(22 / 23)$ & 0.66 & $91.9(68 / 74)$ \\
\hline Diagnostic success rate, \% (n) & $82.6(38 / 46)$ & $100(22 / 22)$ & 0.047 & $88.2(60 / 68)$ \\
\hline Procedural success rate, \% (n) & $70.6(36 / 51)$ & $95.7(22 / 23)$ & 0.02 & $78.4(58 / 74)$ \\
\hline Median time to reach the blind end (IQR), min & $29.5(14.5-41.8)$ & $9.5(6-21)$ & $<0.001$ & $21(10.8-38.3)$ \\
\hline Median ERCP procedure time (IQR), min & $58(36.0-80.0)$ & $42(29.0-63.0)$ & 0.06 & $53(34.0-70.0)$ \\
\hline
\end{tabular}

9.5 minutes (IQR, 6.0-21.0) for the SIF-H290S group. These results indicated better outcomes for the new short SBE group $(P<0.001)$. Median ERCP procedure times were 58.0 minutes (IQR, 36.0-80.0) and 42.0 minutes (IQR, 29.0-63.0) for the SIF-Y0004 group and SIF-H290S group, respectively. Despite the tendency for the ERCP procedure times using the new short SBE to be shorter than using the conventional short SBE, there was no statistically significant difference $(P=0.06)(\triangleright$ Table 4$)$.

Treatments performed included endoscopic sphincterotomy $(n=5)$, endoscopic papillary balloon dilation $(n=8)$, endoscopic papillary large balloon dilation $(n=23)$, stone extraction $(n=32)$, plastic stent placement $(n=9)$, metal stent placement $(n=12)$, and nasobiliary drainage $(n=1)$. There were 17 unsuccessful procedures for the following reasons: inability to insert the scope to the target site $(n=6)$, difficulty with bile duct cannula- tion $(n=9)$, and inability to complete the treatment due to unstable scope control during the procedure following cholangiography $(n=2)$. When using the SIF-H290S, the target site could not be reached in only one case.

\section{Adverse events}

Adverse events occurred at rates of $9.8 \%$ (5/51) and 13\% (3/23) for the SIF-Y0004 and the SIF-H290S, respectively, which did not represent a statistically significant difference $(P=0.70)$. Severity grade of all adverse events were mild. There was one incidence of scope perforation with the SIF-H290S during a stone removal procedure. Fortunately, the perforated part was clipped and healed with conservative treatment ( $\triangleright$ Table 5). 
Table 5 Adverse events ( $n=74$ procedures).

\begin{tabular}{|l|l|l|l|}
\hline & $\begin{array}{l}\text { SIF-Y0004 } \\
(\mathbf{n = 5 1 )}\end{array}$ & $\begin{array}{l}\text { SIF-H290S } \\
\mathbf{( n = 2 3 )}\end{array}$ & P value \\
\hline Pancreatitis, n (\%) & $4(7.8)$ & $1(4.3)$ & $>0.99$ \\
\hline Cholangitis, n (\%) & $1(2.0)$ & $1(4.3)$ & 0.53 \\
\hline Intestinal perforation, n (\%) & $0(0)$ & $1(4.3)$ & 0.31 \\
\hline Total, n (\%) & $5(9.8)$ & $3(13.0)$ & 0.70 \\
\hline
\end{tabular}

\section{Discussion}

With the recent development of the short SBE (which has a working length of $152 \mathrm{~cm}$ and a 3.2-mm working channel) for ERCP-related procedures in patients with surgically altered anatomy, there has been an increase in the number of treatment devices that can be used and the number of treatments that are possible. Furthermore, using a distal attachment cap has been reported to be useful [17]. However, scope insertion and subsequent procedures are more cumbersome than ERCPrelated procedures performed in normal anatomy, therefore, improvements in techniques and devices are needed. To solve this problem, the SIF-H290S was introduced in Japan in 2016. Recently released colonoscopes also have the same features, and they are reportedly useful for passing through parts with high flexion $[18,19]$. Outcomes using the prototype short SBE equipped with passive bending and high-force transmission have been reported [20], and although the therapeutic success rate and other end points were unchanged, it was reported that the scope insertion time was shorter than when using a conventional short SBE. For Roux-en-Y gastrectomy patients, it is especially difficult to reach target sites and perform papilla cannulation and further treatment procedures. Previous reports have indicated that Roux-en-Y gastrectomy patients had treatment success rates ranging from $59.1 \%$ to $88.9 \%$ [11-15]; however, improvements in outcomes are desirable. In this study, outcomes with the new short SBE for Roux-en-Y gastrectomy patients were assessed in comparison to outcomes using a conventional short SBE. These comparisons were used to determine whether the new short SBE contributes to improving outcomes, with procedural success rate as the primary outcome.

This study had an overall procedural success rate of $78.4 \%$ (58/74) for Roux-en-Y gastrectomy patients, which is similar to that of previous reports involving the short SBE. However, the procedural success rate when the new short SBE was used was $95.7 \%$ (22/23), which is better than that of the conventional short SBE used in this study. Diagnostic success rate and median time to reach the blind end were also better when the new short SBE was used. The passive bending feature of the new short SBE makes it easier to pass through flexures in the intestines during scope insertion, thus reducing the time to reach the blind end. In this study, although the same operator performed all procedures from scope insertion to treatment, the operator and an expert exchanged opinions, and the expert provided helpful advice. Although we believe that applying high-force transmission may contribute to improving the procedural success rate and diagnostic success rate because it enables us to perform finer scope operations, the expert's actions also help to enhance the procedural and diagnostic success rates. No previous reports have shown a difference in procedural success rates, therefore, we believe that this indicates the usefulness of the new short SBE. However, insertion in patients with strong adhesions is difficult even with passive bending and high-force transmission, and there is a risk of perforation if forced in such cases. Therefore, treatments with different modalities must be considered, such as percutaneous treatments or endoscopic ultrasonography.

This study has limitations. It was a single-center retrospective study, the sample size with the new short SBE was small, the endoscopists who performed the procedures with the conventional short SBE performed $9 \%$ of the cases with the new short SBE, investigation with a different reconstruction technique (e.g., Billroth-II gastrectomy or pancreaticoduodenectomy) was not possible, and the same patient underwent multiple ERCP-related procedures, such as when completion was not possible with one procedure or cases of recurrent stones after treatment.

In conclusion, Roux-en-Y gastrectomy patients treated with the new short SBE had better outcomes than patients whose procedures involved the conventional short SBE. More cases need to be studied, but the new short SBE has the potential to improve ERCP outcomes for patients with surgically altered anatomy.

\section{Competing interests}

None

\section{References}

[1] Elton E, Hanson BL, Qaseem T et al. Diagnostic therapeutic ERCP using an enteroscope and pediatric colonoscope in long-limb surgical bypass patients. Gastrointest Endosc 1998; 47: 62-67

[2] Wright BE, Cass OW, Freeman ML. ERCP in patients with long-limb Roux-en-Y gastrojejunostomy and intact papilla. Gastrointest Endosc 2002; 56: 225-232

[3] Yamamoto H, Sekine $\mathrm{Y}$, Sato $\mathrm{Y}$ et al. Total enteroscopy with a nonsurgical steerable double-balloon method. Gastrointest Endosc 2001; 53: $216-220$

[4] Aabakken L, Bretthauer M, Line PD. Double-balloon enteroscopy for endoscopic retrograde cholangiography in patients with a Roux-en-Y anastomosis. Endoscopy 2007; 39: 1068 - 1071

[5] Chu YC, Yang CC, Yeh YH et al. Double-balloon enteroscopy application in biliary tract disease - its therapeutic and diagnostic functions. Gastrointest Endosc 2008; 68: 585 - 591

[6] Iwamoto S, Ryozawa S, Yamamoto $\mathrm{H}$ et al. Double balloon endoscope facilitates endoscopic retrograde cholangiopancreatography in rouxen-y anastomosis patients. Dig Endosc 2010; 22: 64-68

[7] Shimatani M, Hatanaka H, Kogure $\mathrm{H}$ et al. Diagnostic and therapeutic endoscopic retrograde cholangiography using a short-type doubleballoon endoscope in patients with altered gastrointestinal anatomy: 
A multicenter prospective study in Japan. Am J Gastroenterol 2016; 111: $1750-1758$

[8] Kawamura T, Yasuda K, Tanaka K et al. Clinical evaluation of a newly developed single-balloon enteroscope. Gastrointest Endosc 2008; 68: $1112-1116$

[9] Wang AY, Sauer BG, Behm BW et al. Single-balloon enteroscopy effectively enables diagnostic and therapeutic retrograde cholangiography in patients with surgically altered anatomy. Gastrointest Endosc 2010; 71: 641 - 649

[10] Saleem A, Baron TH, Goustout C] et al. Endoscopic retrograde cholangiopancreatography using a single-balloon enteroscope in patients with altered Roux-en-Y anatomy. Endoscopy 2010; 42: 656-660

[11] Yamauchi H, Kida M, Okuwaki K et al. Short-type single balloon enteroscope for endoscopic retrograde cholangiopancreatography with altered gastrointestinal anatomy. World J Gastroenterol 2013; 19: $1728-1735$

[12] Iwai T, Kida M, Yamauchi H et al. Short-type and conventional singleballoon enteroscopes for endoscopic retrograde cholangiopancreatography in patients with surgically altered anatomy: single-center experience. Dig Endosc 2014; 26 (Suppl. 02): 156-163

[13] Shimatani M, Takaoka M, Ikeura T et al. Evaluation of endoscopic retrograde cholangiopancreatography using a newly developed short-type single-balloon endoscope in patients with altered gastrointestinal anatomy. Dig Endosc 2014; 26 (Suppl. 02): 147-155
[14] Kawamura T, Uno K, Suzuki A et al. Clinical usefulness of a short-type, prototype single-balloon enteroscope for endoscopic retrograde cholangiopancreatography in patients with altered gastrointestinal anatomy: preliminary experiences. Dig Endosc 2015; 27: 82 - 86

[15] Yane K, Katanuma A, Maguchi $\mathrm{H}$ et al. Short-type single-balloon enteroscope-assisted ERCP in postsurgical altered anatomy: potential factors affecting procedural failure. Endoscopy 2017; 49: 69- 74

[16] Cotton PB, Eisen GM, Aabakken L et al. A lexicon for endoscopic adverse events: report of an ASGE workshop. Gastrointest Endosc 2010; 71: 446-454

[17] Trindade AJ, Mella JM, Slattery E et al. Use of a cap in single-balloon enteroscopy-assisted endoscopic retrograde cholangiography. Endoscopy 2015; 47: 453-456

[18] Sato K, Ito S, Kitagawa T et al. A prospective randomized study on the benefits of a new small-caliber colonoscope. Endoscopy 2012; 44: $746-753$

[19] Mizukami T, Ogata H, Hibi T. "Passive-bending colonoscope" significantly improves cecal intubation in difficult cases. World J Gastroenterol 2012; 18: $4454-4456$

[20] Yamauchi H, Kida M, Okuwaki K et al. Passive-bending, short-type single-balloon enteroscope for endoscopic retrograde cholangiopancreatography in Roux-en-Y anastomosis patients. World J Gastroenterol 2015; 21: 1546-1553 